\title{
PERSEPSI PERAWAT PELAKSANA TENTANG BUDAYA ORGANISASI DAN KINERJA
}

\author{
Ria Utami Panjaitan ${ }^{1 *}$, Budi Anna Keliat ${ }^{1}$, Besral $^{2}$ \\ 1. Departemen Keperawatan Jiwa, FIK-UI, Kampus FIK UI, Jl. Prof. Dr. Bahder Johan, Depok, Jawa Barat - \\ 16424, Indonesia \\ 2. Jurusan Biostatistik FKM-UI, Kampus FKM-UIJl. Prof. Dr. Bahder Johan, Depok, Jawa Barat - 16424, \\ Indonesia \\ *E-mail: riautamip71@gmail.com
}

\begin{abstract}
Abstrak
Mutu pelayanan di rumah sakit tak lepas dari kinerja sumber daya manusia keperawatan. Setiap organisasi memiliki budaya yang merupakan faktor penting yang menentukan keberhasilan organisasidalam mencapai tujuannya. Penelitian yang bertujuan untuk mengidentifikasi hubungan antara persepsi perawat pelaksana tentang budaya organisasi dengan kinerjanya di ruang rawat inap sebuah Rumah Sakit di Bogor ini, merupakan penelitian cross sectional yang melibatkan 113 perawat. Instrumen yang digunakan adalah instrumen budaya organisasi dan kinerja yang telah dimodifikasi. Sebanyak 79,6\% perawat pelaksana mempersepsikan kinerjanya baik dan $85 \%$ mempersepsikan budaya organisasinya baik. Perawat pelaksana yang berpersepsi baik terhadap organisasinya, mereka juga berkinerja lebih baik. Karakteristik perawat pelaksana dan persepsi perawat pelaksana terhadap budaya organisasi tidak berhubungan dengan kinerja. Budaya organisasi yang sudah baik dankinerja yang optimalperlu dipertahankan dengan selalu mengevaluasi tiap komponennya, baik oleh manajemen maupun individu keperawatan.
\end{abstract}

Kata kunci: budaya organisasi, kinerja, perawat pelaksana

\begin{abstract}
The Nurse Practitioners' Perception on Organizational Culture and Work Performance. The quality of hospital services is supported by several aspects, including the work performance of human resources in nursing. Every organization has a culture which is an important factor that determines the success of the organization in achieving its goals. The research aimed to identify the relationship between the perceptions of nurses about the organizational culture with theirwork performance in inpatient ward at a hospital in Bogor, a cross-sectional study involving 113 nurses. The instrument used was the modified instrument of organizational culture and work performance. A total of $79,6 \%$ of nurses perceiving good performance and $85 \%$ perceive the organizational culture good. Nurses who have good perception for the organizational cultura, they also perform better. Characteristics of nurses and nurses' perceptions of the organizational culture is not related to the work performance. Good organizational and optimum work performance need to maintain with evaluating each its component.
\end{abstract}

Keyword: nurse practitioners, organizational culture, work performance

\section{Pendahuluan}

Perawat merupakan tenaga kesehatan yang 24 jam berada bersama klien dan keluarga untuk memberikan pelayanan. Pelayanan keperawatan sebagai bagian integral dari pelayanan kesehatan berkontribusi besar untuk menen-tukan mutu pelayanan rumah sakit
(RS), sehingga setiap upaya untuk meningkatkan mutu pelayanan RS harus disertai dengan upaya meningkatkan mutu pelayanan kepera-watan. Sudah selayaknya evaluasi kinerja perawat menjadi salah satu variabel penting bagi efektifitas organisasi. Penilaian kinerja/prestasi adalah kegiatan mengevaluasi perilaku prestasi kerja karyawan 
serta menetapkan kebijaksanaan selanjutnya, dan penilaian prestasi kerja adalah menilai hasil kerja nyata dengan standar kualitas maupunkuantitas yang dihasilkan oleh setiap karyawan (Mathis \& Jackson, 2008).

Setiap organisasi memiliki budaya, budaya organisasi merupakan hal mendasar yang dalam suatu organisasi dan menjadi penuntun mengacu kepada sistem makna bersama yang dianut oleh anggota yang membedakan organisasi itu terhadap organisasi yang lain dan sebagai filosofi dasar yang mengarahkan kebijakan organisasi (Ravasi \&Schultz, 2006).

Menurut Daud (2004), budaya kerja dalam sebuah organisasi terkait dengan sistem nilai, norma, sikap, dan etika kerja yang dipegang bersama oleh setiap karyawan. Empat elemen ini menjadi asas untuk mengarahkan perilaku karyawan, cara mereka berpikir, berhubungan antara satu sama lain dan berinteraksi dengan sekitarnya. Jika budaya organisasi itu baik, maka akan mengakibatkan karyawannya meningkatkan mutu kerja yang cemerlang dan akan memberikan dampak pada kinerja organisasi.

Penelitian kualitatif tentang dimensi budaya organisasi oleh Sitompul (2003) mengidentifikasi bahwa terdapat enam kategori budaya organisasi pelayanan keperawatan, yaitu visimisi, komunikasi, proses perubahan, kekeluargaan dan senioritas, simbol, dan penghargaan. Susana (2003) mengidentifikasi bahwa faktor yang paling berhubungan dengan budaya kerja perawat dan menjadi prediktor terbentuknya budaya kerja yang konstruktif adalah struktur organisasi,kekompakan, norma kelompok, dan penghargaan. Simbolon, Revida, dan Lubis (2012) menemukan bahwa budaya organisasi memengaruhi kinerja perawat pelaksana di Medan. Berdasarkan ketiga hasil penelitian tersebut maka perlu diuji lebih lanjut tentang budaya organisasi dan pengaruhnya pada budaya kerja karyawan.
Penelitian ini dilakukan di RS kelas A yang didirikan pada tahun 1882 di Kota Bogor.Bed Ocupancy Rate (BOR) $72.61 \%$ (nilai parameter ideal 60-85\%), sedangkan Average Length of Stay (Av LOS) adalah 93.52 hari (LOS nasional untuk RS jiwa adalah 54 hari). Kedua indikator mutu di atas mencerminkan penampilan kinerja RS tersebut menunjukkan BOR sudah mencapai nilai ideal, tetapi lama hari rawat lebih dari standar lama hari rawat nasional. Kondisi klien yang kronis di ruang rawat inap dapat mengakibatkan perawat jenuh, dan kecewa karena pasien tidak segera sembuh. Jika kondisi seperti ini terus menerus terjadi maka akan menurunkan mutupelayanan keperawatan.Tujuan penelitian ini adalah untuk mengidentikasi adanya hubungan antara persepsi perawat pelaksana tentang budaya organisasi dengan kinerjanya di ruang rawat inap.

\section{Metode}

Penelitian cross sectional ini menggunakan budaya organisasi sebagai variabel independen, kinerja perawat pelaksana sebagai variabel dependen, dan karakteristik individu sebagai variabel confounding. Penelitian ini melibatkan 113 responden dengan kriteria inklusi perawat pelaksana di unit rawat inap; berpengalaman kerja minimal setahun; tidak sedang cuti, sakit atau tugas belajar saat penelitian; dan tidak menjabat sebagai kepala ruangan. Sebanyak 15 ruang rawat inap digunakan dalam penelitian ini. Cara pengambilan sampel menggunakan metode random sampling. Penelitian ini telah mendapatkan persetujuan etik dari Komite Etik Penelitian Fakultas Ilmu Keperawatan UI.

Instrumen untuk mengukur budaya organisasi terdiri dari 38 item meliputi kebijakan, simbol status dan sistem penghargaan, norma kelompok, struktur organisasi, komunikasi, dan pernyataan visi-misi, dan kuesioner untuk mengukur kinerja perawat pelaksana yang terdiri dari 50 item meliputi: Prestasi, tanggung jawab, ketaatan, kejujuran, dan kerja 
sama. Hasil uji coba instrumen budaya organisasi bernilai $r$ rentang antara 0,127 sampai 0,818 (r tabel=0,361)dan alpha 0,902. Hasil uji coba instrumen kinerja perawat pelaksana diperoleh nilai $\mathrm{r}$ rentang antara 0,062 sampai 0,874 (tabel=0,361)dan nilai alpha keseluruhan 0,963 .

\section{Hasil}

Karakteristik perawat pelaksana dapat dilihat padatabel 1, persepsi tentang kinerja perawat pelaksana dan budaya organisasi dapat dilihat pada table 2 dan 3 .

Tabel 1. Karakteristik Individu Perawat Pelaksana $(n=113)$

\begin{tabular}{|c|c|c|}
\hline Karakteristik & $\begin{array}{c}\text { Frekuensi } \\
\text { (n) }\end{array}$ & $\begin{array}{c}\text { Persentase } \\
(\%)\end{array}$ \\
\hline \multicolumn{3}{|l|}{ Umur } \\
\hline a. $<26$ tahun & 24 & 21,2 \\
\hline b. 26 sd 45 tahun & 62 & 54.9 \\
\hline c. $>45$ tahun & 27 & 23,9 \\
\hline \multicolumn{3}{|l|}{ Jenis kelamin } \\
\hline a. Laki-laki & 52 & 46,0 \\
\hline b. Perempuan & 61 & 54,0 \\
\hline \multicolumn{3}{|l|}{ Tingkat pendidikan } \\
\hline a. Sekolah Perawat & 23 & 20,4 \\
\hline b. Program Diploma & 82 & 72,6 \\
\hline \multicolumn{3}{|l|}{ Lama kerja } \\
\hline a. $<3$ tahun & 29 & 25,7 \\
\hline b. 3 sd 23 tahun & 59 & 52,2 \\
\hline c. $>23$ tahun & 25 & 22,1 \\
\hline \multicolumn{3}{|l|}{ Status perkawinan } \\
\hline a. Belum Kawin & 28 & 24,8 \\
\hline b. Kawin & 85 & 75,2 \\
\hline \multicolumn{3}{|l|}{ Etnis/suku } \\
\hline a. Sunda & 53 & 46,9 \\
\hline b. Non Sunda & 60 & 53,1 \\
\hline \multicolumn{3}{|l|}{ Ruangan } \\
\hline a. Non MPKP & 95 & 84,1 \\
\hline b. MPKP & 18 & 15,9 \\
\hline \multicolumn{3}{|l|}{ Status kepegawaian } \\
\hline a. PNS & 89 & 78,8 \\
\hline b. Non PNS & 24 & 21,2 \\
\hline
\end{tabular}

Tabel 2. Persepsi Perawat Pelaksana terhadap Kinerja $(\mathrm{n}=113)$

\begin{tabular}{lcc}
\hline \multicolumn{1}{c}{ Komponen Kinerja } & $\begin{array}{c}\text { Frekuensi } \\
(\mathbf{n})\end{array}$ & $\begin{array}{c}\text { Persentase } \\
(\mathbf{\%})\end{array}$ \\
\hline Prestasi kerja & & \\
a. Kurang & 39 & 34,5 \\
b. Baik & 74 & 65,5 \\
Tanggung jawab & & \\
a. Kurang & 14 & 12,4 \\
b. Baik & 99 & 87,6 \\
Ketaatan & & \\
a. Kurang & 20 & 17,7 \\
b. Baik & 93 & 82,3 \\
Kejujuran & & \\
a. Kurang & 20 & 17,7 \\
b. Baik & 93 & 82,3 \\
Kerjasama & & \\
a. Kurang & 22 & 19,5 \\
b. Baik & 91 & 80,5 \\
Komposit & & \\
a. Kurang & 17 & 15,0 \\
b. Baik & 96 & 85,0 \\
\hline
\end{tabular}

Tabel 3. Persepsi Perawat Pelaksana terhadap Budaya Organisasi $(n=113)$

\begin{tabular}{lcc}
\hline \multicolumn{1}{c}{ Komponen Kinerja } & $\begin{array}{c}\text { Frekuensi } \\
(\mathbf{n})\end{array}$ & $\begin{array}{c}\text { Persentase } \\
(\boldsymbol{\%})\end{array}$ \\
\hline Kebijakan & & \\
a. Kurang & 54 & 47,8 \\
b. Baik & 59 & 52,2 \\
Simbol status dan sistem & & \\
penghargaan & 30 & 26,5 \\
a. Kurang & 83 & 73,5 \\
b. Baik & & \\
Norma Kelompok & & \\
a. Kurang & 22 & 19,5 \\
b. Baik & 91 & 80,5 \\
Struktur Organisasi & & \\
a. Kurang & 20 & 17,7 \\
b. Baik & 93 & 82,3 \\
Komunikasi & & \\
a. Kurang & 24 & 21,2 \\
b. Baik & 89 & 78,8 \\
Pernyataan visi dan misi & & \\
a. Kurang & 42 & 37,2 \\
b. Baik & 71 & 62,8 \\
Komposit & & \\
a. Kurang & \\
b. Baik & 23 & 20,4 \\
\hline
\end{tabular}

Tabel 1 menunjukkan sebagian besar perawat berjenis kelamin perempuan (54\%), berusia 26-45 tahun (54,9\%), pendidikan Diploma (72,6\%), lama kerja/pengalaman 3 sampai 23 
tahun $(52,2 \%)$, menikah $(75,2 \%)$, bersuku Sunda $(46,9 \%)$, bekerja di ruang non MPKP $(84,1 \%)$, dan berstatus PNS $(78,8 \%)$.

Kinerja perawat menurut komponen kinerja adalah lebih dari separuh berprestasi kerja baik (65,5\%), bertanggung jawab $(87,6 \%)$, taat $(82,3 \%)$, jujur $(82,3 \%)$, mampu bekerja sama $(80,5 \%)$ pada tabel 2. Secara komposit sebagian besar perawat berkinerja baik $(85,0 \%)$.

Berdasarkan tabel 3, persepsi perawat tentang budaya organisasi menurut komponen budaya organisasi adalah lebih dari separuh mempersepsikan kebijakan baik $(52,2 \%)$, mempersepsikan simbol status dan sistem penghargaan baik $(73,5 \%)$, mempersepsikan norma kelompok baik $(80,5 \%)$, mempersepsikan komunikasi baik $(78,8 \%)$, mempersepsikan pernyataan visi dan misi baik $(62,8 \%)$. Secara komposit mayoritas perawat berpersepsi baik tentang budaya organisasinya $(79,6 \%)$.

Tabel 4 menunjukkan bahwa antara karakteristik perawat pelaksana dengan kinerja tidak ditemukan hubungan $(p>0,05)$. Sementara itu, berdasarkan tabel 5 dapat dilihat bahwa tidak ada hubungan antara persepsi perawat pelaksana tentang budaya organisasi dengan kinerja $(p>0,05)$.

\section{Pembahasan}

Berdasarkan analisis bivariat, tidak ditemukan hubungan antara karakteristik perawat dengan kinerja. Akan tetapi, secara proporsional terlihat bahwa perawat yang lebih muda, berjenis kelamin perempuan, berpendidikan lebih tinggi, mempunyai masa kerja lebih sedikit, belum menikah, bersuku Sunda, bertugas di ruang MPKP, dan berstatus non PNS mempunyai kinerja lebih baik.

Hasil penelitian ini mendukung hasil penelitian sebelumnya. Andriani (2012) menemukan bahwa ada hubungan antara umur dengan kinerja perawat pelaksana di ruang rawat inap di RS di Bukittinggi. Rusdi (2001) menemukan bahwa tidak ada hubungan yang bermakna antara jenis kelamin dan kinerja, namun secara proporsional perawat perempuan berkinerja lebih baik. Hasibuan (2001) mengemukakan bahwa jenis kelamin harus diperhatikan terkait sifat pekerjaan, misalnya untuk pekerjaan merawat pasien yang membutuhkan ketelatenan dan kesabaran yang tinggi, kurang cocok bila dilakukan oleh pria. Keberadaan perawat pria sebagai kelompok minoritas hingga saat ini masih dianggap sensitif, berkaitan dengan emosi dan stereotipe, walaupun di banyak situasi perawat pria justru menunjukkan kinerjanya yang baik (Milligan, 2001 \& Rajacich, Kane, Williston, \& Cameron, 2013).

Berkaitan dengan masa kerja, Nurhaeni (2001) menemukan bahwa perawat yang masa kerjanya kurang dari 11 tahun kinerjanyalebih baik. Masa kerja perawat yang terlalu lama dapat menimbulkan penurunan kinerja akibat kejenuhan karena rutinitas dalam waktu yang lama, sikap pasif dan apatis, mundurnya motivasi dan inisiatif dalam bekerja serta kurangnya kreatifitas perawat karena tidak ada tantangan yang berarti (Shader, et al., 2001). Akan tetapi, penelitian lain menunjukkan justru perawat yang pengalaman kerjanya lebih baik kinerjanya lebih baik (Rudianti, Handiyani, \& Sabri, 2013). Perbedaan ini dapat terjadi akibat perbedaan sifat kerja perawat yang menjadi responden penelitian.

Berkaitan dengan status pernikahan, hasil penelitian ini didukung penelitian sebelumnya yang menemukan bahwa perawat yang belum menikah berkinerja lebih baik (Nurhaeni, 2001; Panjaitan, 2002). Berbeda halnya dengan Rudianti, Handiyani, dan Sabri yang tidak menemukan hubungan diantara kedua variabel tersebut. 
Tabel 4. Hubungan Karakteristik Perawat Pelaksana dengan Kinerja $(\mathrm{n}=113)$

\begin{tabular}{|c|c|c|c|c|c|c|c|}
\hline \multirow{3}{*}{ Karakteristik } & \multicolumn{4}{|c|}{ Kinerja Perawat } & \multirow{3}{*}{ Total } & \multirow{3}{*}{$\underset{(95 \% \mathrm{CI})}{\text { OR }}$} & \multirow{3}{*}{$\mathbf{P}$} \\
\hline & \multicolumn{2}{|c|}{ Kurang } & \multicolumn{2}{|c|}{ Baik } & & & \\
\hline & $\mathrm{N}$ & $\%$ & $\mathrm{n}$ & $\%$ & & & \\
\hline \multicolumn{8}{|l|}{ Umur } \\
\hline$<26$ tahun & 2 & 8.3 & 22 & 91.7 & 24 & $2.5(0.4-14.3)$ & \multirow{3}{*}{0.561} \\
\hline $26-45$ tahun & 10 & 16.1 & 52 & 83.9 & 62 & $1.2(0.4-3.9)$ & \\
\hline$>45$ tahun & 5 & 18.5 & 22 & 81.5 & 27 & & \\
\hline \multicolumn{8}{|l|}{ Jenis kelamin } \\
\hline Laki-laki & 12 & 23.1 & 40 & 76.9 & 52 & $3.4(1,1-10,3)$ & \multirow{2}{*}{0.052} \\
\hline Perempuan & 5 & 8.2 & 56 & 91.8 & 61 & & \\
\hline \multicolumn{8}{|l|}{ Pendidikan } \\
\hline Sekolah Perawat & 7 & 30.4 & 16 & 69.6 & 23 & $3.1(0.3-29.8)$ & \multirow{3}{*}{0,068} \\
\hline Diploma & 9 & 11 & 73 & 89 & 82 & $3.5(1.2-10.9)$ & \\
\hline Sarjana Keperawatan & 1 & 12,5 & 7 & 87.5 & 8 & & \\
\hline \multicolumn{8}{|l|}{ Lama kerja } \\
\hline$<3$ th & 3 & 10.3 & 26 & 89.7 & 29 & $2,1(0,5-10,2)$ & \multirow{3}{*}{0,612} \\
\hline $3 \mathrm{sd} 23$ th & 9 & 15.3 & 50 & 84.7 & 59 & $1,4(0,4-4,7)$ & \\
\hline$>23$ th & 5 & 20 & 20 & 80 & 25 & & \\
\hline \multicolumn{8}{|l|}{ Status perkawinan } \\
\hline Belum Kawin & 2 & 7,1 & 26 & 92.9 & 28 & \multirow{3}{*}{$0.4(0.1-1.7)$} & \multirow{2}{*}{0.233} \\
\hline Kawin & 15 & 17,6 & 70 & 82,4 & 85 & & \\
\hline \multicolumn{7}{|l|}{ Suku } & \\
\hline Sunda & 7 & 13.2 & 46 & 86.8 & 53 & \multirow{3}{*}{$0.8(0.3-2.2)$} & \multirow{3}{*}{0.803} \\
\hline Non Sunda & 10 & 16.7 & 50 & 83.3 & 60 & & \\
\hline \multicolumn{6}{|l|}{ Ruangan } & & \\
\hline Non MPKP & 16 & 16.8 & 79 & 83,2 & 95 & \multirow{3}{*}{$3,4(0,4-27,8)$} & \multirow{3}{*}{0,301} \\
\hline MPKP & 1 & 5.6 & 17 & 94,4 & 18 & & \\
\hline \multicolumn{6}{|l|}{ Status kepegawaian } & & \\
\hline PNS & 14 & 15.7 & 75 & 84.3 & 89 & \multirow{2}{*}{$1,3(0,3-5,0)$} & \multirow{2}{*}{1,000} \\
\hline Non PNS & 3 & 12.5 & 21 & 87.5 & 24 & & \\
\hline
\end{tabular}

Tabel 5. Hubungan Persepsi Perawat Pelaksana tentang Budaya Organisasi dengan Kinerja (n=113)

\begin{tabular}{|c|c|c|c|c|c|c|c|}
\hline \multirow{3}{*}{$\begin{array}{c}\text { Persepsi } \\
\text { Tentang Budaya } \\
\text { Organisasi }\end{array}$} & \multicolumn{4}{|c|}{ Kinerja } & \multirow{3}{*}{ Total } & \multirow{3}{*}{$\begin{array}{c}\text { OR } \\
(95 \% \mathrm{CI})\end{array}$} & \multirow{3}{*}{$P$} \\
\hline & \multicolumn{2}{|c|}{ Kurang } & \multicolumn{2}{|c|}{ Baik } & & & \\
\hline & $\mathrm{n}$ & $\%$ & $\mathrm{n}$ & $\%$ & & & \\
\hline \multicolumn{8}{|l|}{ Kebijakan } \\
\hline Kurang & 11 & 20,4 & 43 & 79,6 & 54 & \multirow{2}{*}{$2,3(0,8-6,6)$} & \multirow{2}{*}{0,21} \\
\hline Baik & 6 & 10,2 & 53 & 89,8 & 49 & & \\
\hline \multicolumn{8}{|c|}{$\begin{array}{l}\text { Simbol status dan sistem } \\
\text { penghargaan }\end{array}$} \\
\hline Kurang & 7 & 23,3 & 23 & 76,7 & 30 & \multirow{2}{*}{$2,2(0,8-6,5)$} & \multirow{2}{*}{0,15} \\
\hline Baik & 10 & 12,0 & 73 & 88,0 & 83 & & \\
\hline \multicolumn{8}{|l|}{ Norma Kelompok } \\
\hline Kurang & 5 & 22,7 & 17 & 77,3 & 22 & \multirow{2}{*}{$1,9(0,6-6,2)$} & \multirow{2}{*}{0,32} \\
\hline Baik & 12 & 13,2 & 79 & 86,8 & 91 & & \\
\hline \multicolumn{8}{|l|}{ Struktur Organisasi } \\
\hline Kurang & 5 & 25,0 & 15 & 75,0 & 20 & \multirow{2}{*}{$2,3(0,7-7,3)$} & \multirow{2}{*}{0,18} \\
\hline Baik & 12 & 12,9 & 81 & 87,1 & 93 & & \\
\hline \multicolumn{8}{|l|}{ Komunikasi } \\
\hline Kurang & 5 & 20,8 & 19 & 79,2 & 24 & \multirow{2}{*}{$1,7(0,5-5,4)$} & \multirow{2}{*}{0,35} \\
\hline Baik & 12 & 13,5 & 7 & 86,5 & 89 & & \\
\hline \multicolumn{8}{|c|}{ Pernyataan visi dan misi } \\
\hline Kurang & 8 & 19,0 & 34 & 81,0 & 42 & \multirow{2}{*}{$1,6(0,6-4,6)$} & \multirow{2}{*}{0,52} \\
\hline Baik & 9 & 12,7 & 62 & 87,3 & 71 & & \\
\hline
\end{tabular}



Hasil penelitian menunjukkan bahwa secara proporsional hampir semua perawat pelaksana yang bertugas di ruang Model Praktik Keperawatan Profesional (MPKP) mempunyai kinerja baik. Fatiah (2002) dalam penelitiannya menemukan bahwa perawat yang bertugas di ruang MPKP memiliki pengetahuan, kinerja, dan kepuasan kerja yang lebih tinggi. Keliat dan Akemat (2009) mengemukakan manajemen kegiatan keperawatan di ruang model praktik keperawatan profesional berdasarkan empat pilar nilai profesional yaitu pendekatan manajemen, kompensasi dan penghargaan, hubungan profesional, dan pemberian asuhan keperawatan. Peneliti berpendapat sistem yang diciptakan di ruang MPKP memengaruhi kinerja perawat.

Penelitian ini menunjukkan secara proporsional perawat non PNS berkinerja lebih baik. Makhrus (2002) dalam penelitiannya menemukan bahwa perawat yang berstatus pegawai kontrak kinerjanya lebih baik daripada perawat yang berstatus PNS.

Hubungan antara persepsi perawat pelaksana tentang budaya organisasi dan kinerja diuraikan di bawah ini. Hasil penelitian tentang komponen kebijakan menunjukkan bahwa secara proporsional perawat yang mempunyai persepsi baik terhadap kebijakan berkinerja lebih baik. Sitompul (2003) menemukan bahwa kebijakan memengaruhi kinerja perawat. Kebijakan tersebut terkait dengan peraturan, sanksi, penghargaan, dan supervisi. Hasil ini didukung oleh Rudianti, Handiyani, dan Sabri (2013) yang mengidentifikasi bahwa supervisi dan pengarahan merupakan faktor yang paling berpengaruh terhadap kinerja perawat. Demikian pula Susana (2003) yang menemukan bahwa penghargaan berhubungan positif dengan budaya kerja. Sitompul (2003) menemukan bahwa sebagian besar perawat menyatakan kompensasi yang diterima belum sesuai dengan harapan. Terkait dengan simbol status perawat umumnya bangga bekerja di sebuah
RS yang merupakan pusat rujukan nasional untuk kasus ginjal.

Hasil penelitian juga menemukan bahwa perawat yang mempunyai persepsi baik terhadap norma kelompok berkinerja baik. Susana (2003) dalam penelitiannya di Bandung menemukan bahwa norma kelompok merupakan variabel yang valid dalam memprediksi budaya kerja perawat pelaksana. Variabel tersebut mempunyai hubungan dengan budaya kerja perawat pelaksana. Adanya hubungan tersebut diasumsikan karena kuatnya norma dan nilai-nilai yang ada. Norma yang dikembangkan tercermin dari beberapa kebiasaan yang sampai saat ini tetap dipelihara, misalnya ibadah pagi, penggunaan waktu kerja, penggunaan seragam dinas, nilai kebersamaan dan toleransi antar kelompok. Menurut Daud (2004), norma merupakan nilai yang diterima oleh mayoritas anggota kelompok yang disepakati karena mencerminkan keinginan kelompok. Dengan kata lain, norma adalah peraturan hidup dan amalan yang diterima masyarakat.

Penelitian ini juga menemukan bahwa perawat yang berpersepsi baik terhadap struktur organisasi berkinerja lebih baik. Hasil penelitian Nurhaeni (2001) menunjukkan bahwa struktur organisasi tidak berhubungan bermakna dengan kinerja, namun secara proporsional perawat yang berpersepsi baik terhadap struktur organisasi mempunyai kinerja yang lebih baik. Masitoh (2002) dalam menemukan bahwa struktur organisasi berhubungan bermakna dengan kinerja dan perawat yang berpersepsi baik terhadap struktur organisasi mempunyai kinerja yang lebih baik. Sementara Susana (2003), menemukan bahwa kesepakatan staf dengan dengan struktur organisasi tempat mereka bekerja berhubungan positif dengan budaya kerja.

Hasil penelitian menunjukkanbahwa perawat yang berpersepsi baik terhadap komunikasi kinerjanya lebih baik. Sitompul (2003) 
menemukan bahwa perawat pelaksana yang dapat mampu berkomunikasi merupakan budaya yang sangat menunjang organisasi. Komunikasi dapat berupa rapat, sosialisasi informasi, pemberian teguran, ritual rumah sakit.

Hasil penelitian mendapatkan bahwaperawat yang berpersepsi baik terhadap pernyataan visi dan misi berkinerja lebih baik. Hasil ini sejalan dengan Sitompul (2003) yang menemukan bahwa perawat berpendapat bahwa visi dan misi organisasinya memberi arah dalam bekerja.

Hasil penelitian ini memberikan dampak pada aspek pelayanan keperawatan. Manajemen RS perlu mengambil data secara seimbang baik dari struktural maupun karyawannnya, termasuk perawat untuk menilai bagaimana budaya organisasi sudah berjalan. Penilaian kinerja melalui para perawat sendiri juga merupakan penghargaan atas kemampuan perawat untuk menilai diri mereka sendiri.

Perbedaan hasil penelitian ini dengan penelitian sebelumnya dapat terjadi karena beberapa keterbatasan. Penelitian yang hanya dilakukan di satu RS yang mempunyai spesifikasi khusus dan berbeda dengan RS lain pada umumnya membuat hasil penelitian ini belum menggambarkan situasi secara keseluruhan di Indonesia. Budaya organisasi, dan kinerja merupakan persepsi responden tentang pengalaman yang dirasakan serta tindakan yang dilakukan, sehingga kualitas data tergantung pada kejujuran, keberanian, dan kemampuan daya ingat responden dalam memberikan jawaban tentang dirinya.

\section{Kesimpulan}

Sebagian besar perawat pelaksana mempunyai persepsi baik terhadap budaya organisasi dan kinerjanya di ruang rawat inap, mereka ini menunjukkan kinerja lebih baik dibanding perawat yang mempunyai persepsi kurang walaupun secara statistik tidak ditemukan hubungan antara karakteristik individu dan persepsi perawat pelaksana terhadap budaya organisasi dengan kinerja.

Budaya organisasi yang sudah baik perlu dipertahankan dengan terus mengupayakan perbaikan di setiap komponennya. Bagi komponen yang sebagian besar masih dipersepsikan kurang (kebijakan dan pernyataan visi-misi) dapat dievaluasi dan diperbaiki dengan mempertimbangkan aspirasi perawat agar semua perawat merasa memiliki dan mempunyai komitmen.

Disarankan juga agar menggali lebih dalam motivasi perawat pria pada saat rekrutmen dan mendukung mereka secara emosional agar dapat memeroleh makna dalam bekerja sehingga kinerjanya lebih baik. Hal lain yang menjadi hak perawat juga perlu ditunaikan seperti kesempatan untuk meningkatkan pendidikan formal maupun informal, pengembangan kompetensi, penghargaan yang sesuai, dan melaksanakan metode penugasan di ruangan dengan konsisten dan sesuai kaidah. Perawat punperlu mempertahankan kinerja yang sudah baik dan secara terusmenerus memperbaikinya, khususnya komponen prestasi kerja.

Penelitian kualitatif terkait budaya organisasi keperawatan di Indonesia perlu dilakukan selanjutnya. Penelitian yang lain juga diperlukan untuk mengidentifikasi faktor lain yang berhubungan dengan kinerja perawat; atau menilai kinerja perawat dengan menggunakan metode observasi (INR, MS)

\section{Referensi}

Andriani, M., Sahar, J., Huriani, E. (2012). Hubungan budaya organisasi dan karakteristik perawat dengan perawat pelaksana di ruang rawat inap RSUD Dr. Achmad Mochtar Bukittinggi tahun 2012. Diperoleh dari http://repository.unand.ac.id/19905/BAB1.pdf 
Daud, Z. M. (2004). Budaya kerja cemerlang. Diperoleh dari http://inturalibraryO.tripod .com/artikel/budaya-kerja-cemerlang.htm.

Fatiah. (2002). Hubungan antara pengetahuan, persepsi, dan sikap perawat terhadap model praktik keperawatan professional dengan kinerja dan kepuasan kerja perawat di RSMM Bogor. (Tesis magister, tidak dipublikasikan). Program Pasca Sarjana UGM, Yogyakarta, Indonesia.

Hasibuan, M. S. P. (2001). Manajemen sumber daya manusia. Edisi revisi. Jakarta: PT Bumi Aksara.

Keliat, B. A., \&Akemat. (2009). Model praktek keperawatan profesional jiwa. Jakarta: EGC.

Makhrus, I. (2002). Analisis iklim komunikasi dalam organisasi keperawatan dengan kinerja perawat pelaksana di instalasi rawat inap RSUD Karawang. (Tesis magister, tidak dipublikasikan). FIK-Universitas Indonesia, Depok, Jawa Barat, Indonesia.

Masitoh, S. (2002). Analisis kinerja perawat pelaksana dan hubungannya dengan karakteristik demografis dan karakteristik organisasi di ruang rawat inap RSAB Harkit Jakarta. (Tesis magister, tidak dipublikasikan). FIK-Universitas Indonesia, Depok, Jawa Barat, Indonesia.

Mathis, R.L., \& Jackson, J.H. (2008). Mathis's \& Jackson's human resource management: Essential perspectives. $5^{\text {th }}$ ed. Cincinnati: South-Western College Pub.

Milligan, F. (2001). The concept of care in male nurse work: an ontological hermeneutic study in acute hospitals. Journal of Advanced Nursing, 35(1), 7-16. doi: 10.1046/j.13652648.2001.01818.x

Nurhaeni. (2001). Faktor-faktor determinan yang berhubungan dengan kinerja perawat pelaksana di RSI Makasar tahun 2001. (Tesis magister, tidak dipublikasikan). FIKUniversitas Indonesia, Depok, Jawa Barat, Indonesia.

Panjaitan, R. (2002). Hubungan efektifitas kepemimpinan kepala ruangan dengan kinerja perawat pelaksana di ruang rawat inap RSPADGS Jakarta. (Tesis magister, tidak dipublikasikan). FIK-Universitas Indonesia, Depok, Jawa Barat, Indonesia.

Rajacich, D., Kane, D., Williston, C., \& Cameron, S. (2013). If They Do Call You a Nurse, It Is Always a "Male Nurse": Experiences of Men in the Nursing Profession. Nursing Forum, 48(1), 71-80. doi: 10.1111/nuf.12008

Ravasi, D., \& Schultz, M. (2006). Responding to organizational identity threats: Exploring the role of organizational culture. Academy of Management Journal 49 (3): 433-458. doi: 10.5465/AMJ.2006.21794663

Rudianti Y., Haniyani, H., \& Sabri, L. (2013). Peningkatan kinerja perawat pelaksana melalui komunikasi organisasi di ruang rawat inap rumah sakit. Jurnal Keperawatan Indonesia, 16(1), 25-32.

Rusdi, I. (2001). Determinan kinerja perawat di RSUD Ciawi Kabupaten Bogor tahun 2001. (Tesis magister, tidak dipublikasikan). FIKUniversitas Indonesia, Depok, Jawa Barat, Indonesia.

Shader, K., Broome, M. E., Broome, C. D., West, M. E., \& Nash, M. (2001). Factors Influencing Satisfaction and Anticipated Turnover for Nurses in an Academic Medical Center. Journal of Nursing Administration, 31(4), 210$216 . \quad$ Diperoleh dari https://www.ncbi.nlm.nih.gov/pubmed/113243 34

Simbolon, R. Revida, E., \&Lubis, M. (2012). Pengaruh budaya organisasi terhadap kinerja perawat pelaksana di ruang rawat inap $R S S t$ Elisabeth Medan tahun 2012. Diperoleh dari http://repository.usu.ac.id/handle/123456789/3 5052.

Sitompul, R. (2003). Analisis dimensi budaya organisasi pelayanan keperawatan di RS PGI Cikini Jakarta tahun 2002. (Tesis magister, tidak dipublikasikan). FIK-Universitas Indonesia, Depok, Jawa Barat, Indonesia.

Susana, A. (2003). Faktor-faktor yang berhubungan dengan budaya kerja perawat pelaksana di ruang rawat inap RS Immanuel 
Bandung. (Tesis magister, tidak dipublikasikan). FIK-Universitas Indonesia, Depok, Jawa Barat, Indonesia. 